\title{
CRESCIMENTO E PRODUÇÃO DE COQUEIRO ANÃO VERDE FERTIRRIGADO COM NITROGÊNIO E POTÁSSIO
}

\section{GROWTH AND PRODUCTION OF COCONUT DWARF GREEN FERTIGATION WITH NITROGEN AND POTASSIUM}

\author{
Sammy Sidney Rocha MATIAS ${ }^{1}$ \\ Boanerges Freire de AQUINO ${ }^{2}$ \\ José de Arimatéia Duarte de FREITAS ${ }^{3}$
}

\begin{abstract}
RESUMO
A deficiência de nitrogênio e potássio na fase inicial do desenvolvimento do coqueiro poderá prejudicar a fisiologia da planta diminuindo a produção. O objetivo deste trabalho foi avaliar a aplicação de nitrogênio e de potássio, via fertirrigação, sobre o desenvolvimento vegetativo, aos três anos, e a produção do coqueiro anão verde, aos quatro anos de idade, cultivado em Neossolo quartzârenico. O trabalho foi realizado em plantação comercial do coqueiro anão verde do Jiqui, no município de Paracuru (CE). O delineamento experimental foi de blocos casualizados, com 10 tratamentos consistindo de cinco doses de nitrogênio e potássio, combinadas, de acordo com modelo da matriz experimental Plan Puebla III. Foram avaliadas a cada quatro meses as seguintes características: altura da planta, circunferência do coleto, número de folhas, número de folíolos na folha 3 , aos três anos de idade e número de flores feminina, número de cachos por planta, número de frutos por planta, massa do fruto, circunferências do fruto (equatorial e polar), volume de água do fruto, sólidos solúveis totais, com quatro anos de idade. As doses de $\mathrm{N}$ e $\mathrm{K}$ aplicadas no solo não afetaram o número de cachos. $\mathrm{O}$ aumento do $\mathrm{N}$ proporcionou um crescimento linear nas variáveis altura, circunferência do coleto, número de folhas e número de folíolos na folha 3. As maiores doses de $\mathrm{N}$ promoveram a diminuição das variáveis de produção com exceção do sólidos solúveis totais. As maiores doses de $\mathrm{K}_{2} \mathrm{O}$ resultaram em um aumento do número de frutos por planta e sólidos solúveis totais.
\end{abstract}

Palavras - chave: Cocos nucifera L.; Nutrição; fertirrigação; N; K.

\begin{abstract}
The nitrogen and potassium deficient in initial growth phase of coconut palm could spoil all the plant physiology resulting in production decrease. The objective of this study was to evaluate the application of nitrogen and potassium fertigation on plant development, at three, and the production of dwarf green, four years old, grown in a soil classified as Quartzipsament. The work was conducted in the commercial planting of green coconut dwarf of Jiqui, in the municipality of Paracuru, (CE). The experimental design was randomized blocks, with 10 treatments consisting of five combined doses of nitrogen and potassium, according to Plan Puebla III experimental matrix model. Were evaluated every four months the following characteristics: plant height, trunk perimeter, number of leaves, number of leaflets on the leave 3 , to three years of age and number of female flowers, number of bunch per plant, fruit number per plant, fruit weight, fruit perimeter (equatorial and polar), fruit water volume, soluble solids, with four years of age. The doses of $\mathrm{N}$ and $\mathrm{K}$ applied to the soil not affect the number of clusters. The increase in $\mathrm{N}$ resulted in a linear increase in the variables height, circumference of the girth, leaf number and leaflet number leaf 3 . The higher $\mathrm{N}$ rates promoted the reduction of production variables except the soluble solids. The highest doses of $\mathrm{K}_{2} \mathrm{O}$ resulted in a significant increase in the number of fruits per plant and total soluble solids.
\end{abstract}

Key - words: Cocos nucifera L.; Nutrition; fertigation; N; K.

\footnotetext{
1 Doutorando do Programa de Pós-Graduação em Agronomia (Produção Vegetal) da Faculdade Ciências Agrárias e Veterinárias (FCAV)/ Universidade Estadual Paulista "Júlio de Mesquita Filho" (Unesp), Campus de Jaboticabal, Dept ${ }^{\circ}$ Solos e Adubos. Rua Três, n 11, Bairro Nova Corrente, CEP 64980-000, Corrente, Piauí, Brasil. E-mail: ymmsa2001@yahoo.com.br. Autor para correspondência

${ }^{2}$ Eng. Agrônomo, Ph.D., Prof. Dep. de Ciência do Solo, Centro de Ciências Agrárias (CCA) /Universidade Federal do Ceará (UFC), Fortaleza, Ceará, Brasil. E-mail: aquino@ufc.br.

${ }^{3}$ Eng. Agrônomo, DSc., Pesquisador da Embrapa Agroindústria Tropical, Fortaleza, Ceará, Brasil. E-mail: ari@cnpat.embrapa.br.
} 
MATIAS, S.S.R. et al. Crescimento e produção de coqueiro...

\section{INTRODUÇÃO}

O coqueiro anão vem se expandido no Brasil principalmente nas regiões Norte e Sudeste, devido às condições climáticas, e a grande demanda pelas agroindústrias do seguimento de envasamento de água de coco. No entanto, a região Nordeste possui a maior área cultivada, sendo responsável por mais de $70 \%$ da produção de cocos no Brasil (IBGE, 2007). Apesar dessas vantagens a viabilidade econômica da cultura está associada ao seu estado e ao ambiente que segundo Teixeira \& Silva (2003) e Teixeira et al. (2005) não interfere apenas seu crescimento vegetativo, mas também na produção por planta e na qualidade da água do fruto.

A carência de nitrogênio na planta de acordo com Sobral (2003) além de provocar clorose gradual nas folhas inibe a emissão de flores femininas, se refletindo na diminuição do tamanho das folhas e estreitamento do estipe. Quanto ao potássio sua deficiência na fase de produção do coqueiro ocasiona diminuição da emissão de flores e em conseqüência, produção por planta, volume e qualidade da água (Villas Bôas et al., 2001).

Pelo exposto, o crescimento e produção do coqueiro dependem das estruturas morfológicas ou anatômicas, como altura, diâmetro, folhas, flores e frutos. Estas variáveis exercem expressiva importância nas descrições da fenologia, como nos diferentes tipos e níveis tecnológicos de manejos da cultura. De acordo com Carrijo et al. (1999), o desequilíbrio nutricional e a deficiência de água na maioria das regiões cultivadas com coco no Nordeste exigem do produtor adoção de tecnologias como a fertirrigação.

O objetivo deste trabalho foi avaliar a aplicação de nitrogênio e de potássio, via fertirrigação, sobre o desenvolvimento vegetativo, aos três anos, e a produção do coqueiro anão verde, aos quatro anos de idade, cultivado em Neossolo quartzârenico.

\section{MATERIAL E MÉTODOS}

O experimento foi desenvolvido no período de janeiro de 2002 a dezembro de 2003 no município de Paracuru (CE), situados pelas coordenadas geográficas $3^{\circ} 17^{\prime} 00^{\prime \prime}$ de latitude sul, $39^{\circ} 15^{\prime} 00^{\prime \prime}$ de longitude oeste e altitude media de $30 \mathrm{~m}$, em uma plantação comercial de coqueiro anão verde do Jiqui. O clima da região é classificado segundo Koeppen como AW, caracterizado como tropical chuvoso. O espaçamento utilizado foi de $7,0 \times 9,5 \mathrm{~m}$, perfazendo um total de 342 plantas, das quais 102 foram bordadura. Sendo o experimento avaliado de janeiro a dezembro de 2002 e 2003. O solo da região foi classificado como Neossolo quartzarênico (Santos et al., 2006).

Os tratamentos consistiram de cinco doses de nitrogênio associados com cinco doses de potássio (10 tratamentos), usando o modelo da matriz experimental Plan Puebla III, modificado por Leite (1984), correspondendo a um fatorial $2^{k}+2 k+1+1$ (sendo $k$ o número de fatores estudados). Os intervalos de doses dos nutrientes foram: para N (90 a 1710 e 150 a $2850 \mathrm{~g}$ por planta por ano) e para $\mathrm{K}_{2} \mathrm{O}$ (120 a 2280 e 250 a $4750 \mathrm{~g}$ por planta por ano), aplicados nos anos de 2002 e 2003 referentes ao terceiro e quarto ano da cultura (Tabela 1), sendo utilizado, como base da obtenção das doses, o Tratamento T9 (900 e 1500 g por planta por ano de $\mathrm{N}$ e 1200 e $2500 \mathrm{~g}$ por planta por ano), o qual consistia da dose mais recomendada para esta cultura (Tabela 1) de acordo com estudos prévios da Embrapa Agroindústria Tropical de Fortaleza. O delineamento utilizado foi o de blocos inteiramente casualisados, com quatro repetições, totalizando 40 unidades experimentais, sendo utilizada 6 plantas por tratamento.

TABELA 1 - Níveis da matriz e doses de $\mathrm{N}$ e $\mathrm{K}_{2} \mathrm{O}$ calculadas de acordo com a matriz experimental Plan Puebla III, modificada por Leite (1984).

\begin{tabular}{ccccccc}
\hline Tratamento & \multicolumn{2}{c}{--- -Níveis--- } & \multicolumn{2}{c}{-Doses de $\mathrm{N}$ g por planta por ano } & \multicolumn{2}{c}{-Doses $\mathrm{K}_{2} \mathrm{O}$ g por planta por ano } \\
& $\mathrm{N}$ & $\mathrm{K}_{2} \mathrm{O}$ & $3^{\circ}$ ano & $4^{\circ}$ ano & $3^{\circ}$ ano & $4^{\circ}$ ano \\
\hline T1 & $-0,4$ & $-0,4$ & 540 & 900 & 720 & 1500 \\
T2 & $-0,4$ & 0,4 & 540 & 900 & 1680 & 3500 \\
T3 & 0,4 & $-0,4$ & 1260 & 2100 & 720 & 1500 \\
T4 & 0,4 & 0,4 & 1260 & 2100 & 1680 & 3500 \\
T5 & $-0,9$ & $-0,4$ & 90 & 150 & 720 & 1500 \\
T6 & 0,9 & 0,4 & 1710 & 2850 & 1680 & 3500 \\
T7 & $-0,4$ & $-0,9$ & 540 & 900 & 120 & 250 \\
T8 & 0,4 & 0,9 & 1260 & 2100 & 2280 & 4750 \\
T9 & 0 & 0 & 900 & 1500 & 1200 & 2500 \\
T10 & $-0,9$ & $-0,9$ & 90 & 150 & 120 & 250 \\
\hline
\end{tabular}


MATIAS, S.S.R. et al. Crescimento e produção de coqueiro...

As doses de $\mathrm{N}$ e $\mathrm{K}$ foram aplicadas semanalmente na forma de uréia e cloreto de potássio na época de estiagem utilizando o próprio sistema de irrigação, as doses indicadas na Tabela 1 , foram aplicadas durante três meses e fornecidas duas vezes por semana. Foi realizada uma adubação básica com fósforo e enxofre, nas quantidades de 150 e $190 \mathrm{~g}$ por planta por ano, no terceiro ano do experimento, como forma de supri as necessidades destes nutrientes, com base em análises feitas antes do experimento.

A fertirrigação foi feita semanalmente por microaspersão, com um emissor por planta, instalado a $40 \mathrm{~cm}$ do caule do coqueiro, com vazão de $50 \mathrm{dm}^{3} \mathrm{~h}^{-1}$ e raio de alcance de $3 \mathrm{~m}$. A freqüência da fertirrigação foi semanal. Para cada tratamento houve uma linha de distribuição de água, separada, com um ponto de injeção no início da linha, usando uma bomba injetora de acionamento hidráulico com capacidade para $50 \mathrm{dm}^{3} \mathrm{~h}^{-1}$ (modelo TMB WP-10).

O crescimento foi avaliado, a cada quatro meses, nas plantas com três anos de idade durante o ano de 2002 e a produção também no mesmo intervalo no ano de 2003. As variáveis relativas ao crescimento foram: foram: número de flores femininas (NFF), número de cachos por planta (NCP) e número de frutos por planta (NFP), massa do fruto (MF) e circunferência do fruto (C. equatorial e C. polar), volume de água (VA), sólidos solúveis totais ( ${ }^{\circ}$ Brix).

A altura da planta medida com uma fita métrica presa a uma áster: feita a partir da base da planta até a folha mais alta; circunferência do coleto: efetuada a $5 \mathrm{~cm}$ do solo, com auxílio de uma fita métrica; número de folhas: número de folhas verdes e adultas com mais de $50 \%$ da folha aberta; número de folíolos na folha três: contagem de folíolos da folha 3 , ou seja, a terceira folha completamente aberta a partir do ápice da planta; número de folíolos na folha três: contagem de folíolos da folha 3 , ou seja, a terceira folha completamente aberta a partir do ápice da planta; número de flores femininas: contagem das flores abertas; número de cachos por planta: contagem de todos os cachos em início de produção; número de frutos por planta: contagem de todos os frutos sadios coletados por cachos; massa do fruto: escolha de três frutos aleatórios entre os coletados; circunferências dos frutos foi medidas com o auxilio de uma fita métrica: determinados nos frutos escolhidos aleatoriamente; volume de água do fruto: retirada da água dos frutos escolhidos aleatoriamente; 'Brix: retirada uma amostra de água dos frutos coletados aleatoriamente e verificada com o refratômetro manual.

Os resultados foram submetidos à análise estatística pelo programa SAS (SAS Institute, 1995), sendo os efeitos dos diferentes níveis de $\mathrm{N} \mathrm{e}$ $\mathrm{K}_{2} \mathrm{O}$ analisados pelos métodos convencionais da análise de variância (teste $F$ ), aplicando-se o teste de regressão polinomial.

\section{RESULTADOS E DISCUSSÃO}

Foram observadas durante a condução do experimento condições edafoclimáticas adequadas à cultura do coqueiro, sendo observados temperaturas máximas e mínimas de $34,3-21,4{ }^{\circ} \mathrm{C}$ e $33,5-21,4{ }^{\circ} \mathrm{C}$; a umidade relativa média 69 e $70 \%$; respectivamente no terceiro e quarto ano do experimento. O período chuvoso foi de janeiro a julho nos dois anos estudados tendo uma precipitação de 1500 e $1700 \mathrm{~mm}$ respectivamente; entretanto observou-se uma distribuição irregular das chuvas, sendo a disponibilidade da água suprida por irrigação. Os valores obtidos para as condições edafoclimáticas do experimento estão todos dentro das faixas ótimas (Child, 1974; Fremond et al., 1975 e Ochs, 1977).

Através dos resultados da análise de variância (Tabela 2), não se observa efeito significativos para variável número de cachos por planta (NCP), porém foi constatado efeito significativo das doses de $\mathrm{N}$ para altura (ALT.), circunferência do coleto (CC), número de folhas (NF); número de folíolos na folha 3 (NFOL), números de flores femininas (NFF), massa do fruto (MF), circunferências equatorial do fruto (CEF) e polar do fruto (CPF), volume de água no fruto (VA) e sólidos solúveis totais ( ${ }^{\circ} \mathrm{Brix}$ ); as doses de $\mathrm{K}_{2} \mathrm{O}$ exerceram uma influencia significativa sobre as variáveis, número de frutos por planta (NFP), massa do fruto (MF), circunferências equatorial do fruto (CEF) e polar do fruto (CPF), volume de água no fruto (VA) e sólidos solúveis totais ('Brix), estes resultados estão de acordo com os observados por Silva et al. (2006), que obteve efeito quadrático dos dois nutrientes para as variáveis (MF, VA e ${ }^{\circ}$ Brix).

TABELA 2 - Resumo da análise de variância (teste F) para produção e crescimento do coqueiro anão em função das doses $\mathrm{N}$ e $\mathrm{K}_{2} \mathrm{O}$. Dados coletados a cada quatro meses $-3^{\circ}$ e $4^{\circ}$ ano (média anual). Paracuru, CE.

\begin{tabular}{ccccccccccccc}
\hline Fonte de variação & ALT & CC & NF & NFOL & NFF & NFP & NCP & MF & CEF & CPF & VA & ${ }^{\circ}$ Brix \\
\hline Linear N & $*$ & $*$ & $*$ & $*$ & ns & ns & ns & ns & ns & ns & ns & ns \\
Quadrática N & ns & ns & ns & ns & $*$ & ns & ns & $*$ & $*$ & $*$ & $*$ & $*$ \\
Linear K & ns & ns & ns & ns & ns & ns & ns & ns & ns & ns & ns & ns \\
Quadrática K & ns & ns & ns & ns & ns & $*$ & ns & $*$ & $*$ & $*$ & $*$ & $*$ \\
\hline
\end{tabular}

ALT: Altura; CC: Circunferência do coleto; NF: Número de folhas; NFOL: Número de folíolos na folha 3; NFF: número de flores femininas; NFP: número de frutos por planta; NCP: número de cachos por plantas; MF: massa do fruto; CEF: circunferência equatorial do fruto; CPF: circunferência polar do fruto; VA: volume de água; ${ }^{\circ B}$ rix: sólidos solúveis totais. ns Não significativo $e^{*}$ significativo a 0,05 de probabilidade pelo teste $\mathrm{F}$, respectivamente. 
MATIAS, S.S.R. et al. Crescimento e produção de coqueiro...

Para as variáveis de crescimento (ALT, CC, NF e NFOL), não foi observado efeito significativo para o modelo quadrático (Tabela 2). Observou-se, entretanto, que o desenvolvimento do coqueiro anão foi influenciado somente pela aplicação de $\mathrm{N}$ $(P<0,05)$, o qual foi evidenciado por todas as características de crescimento (Figura 1 A, B, C e
D), as quais aumentaram linearmente em relação às doses de $\mathrm{N}$ aplicadas. Estes mesmos resultados foram obtidos em experimentos semelhantes por Sobral (2003); Ramos et al. (2004) e Alves et al. (2007), demonstrando que o $\mathrm{N}$ influencia no desenvolvimento desta cultura.
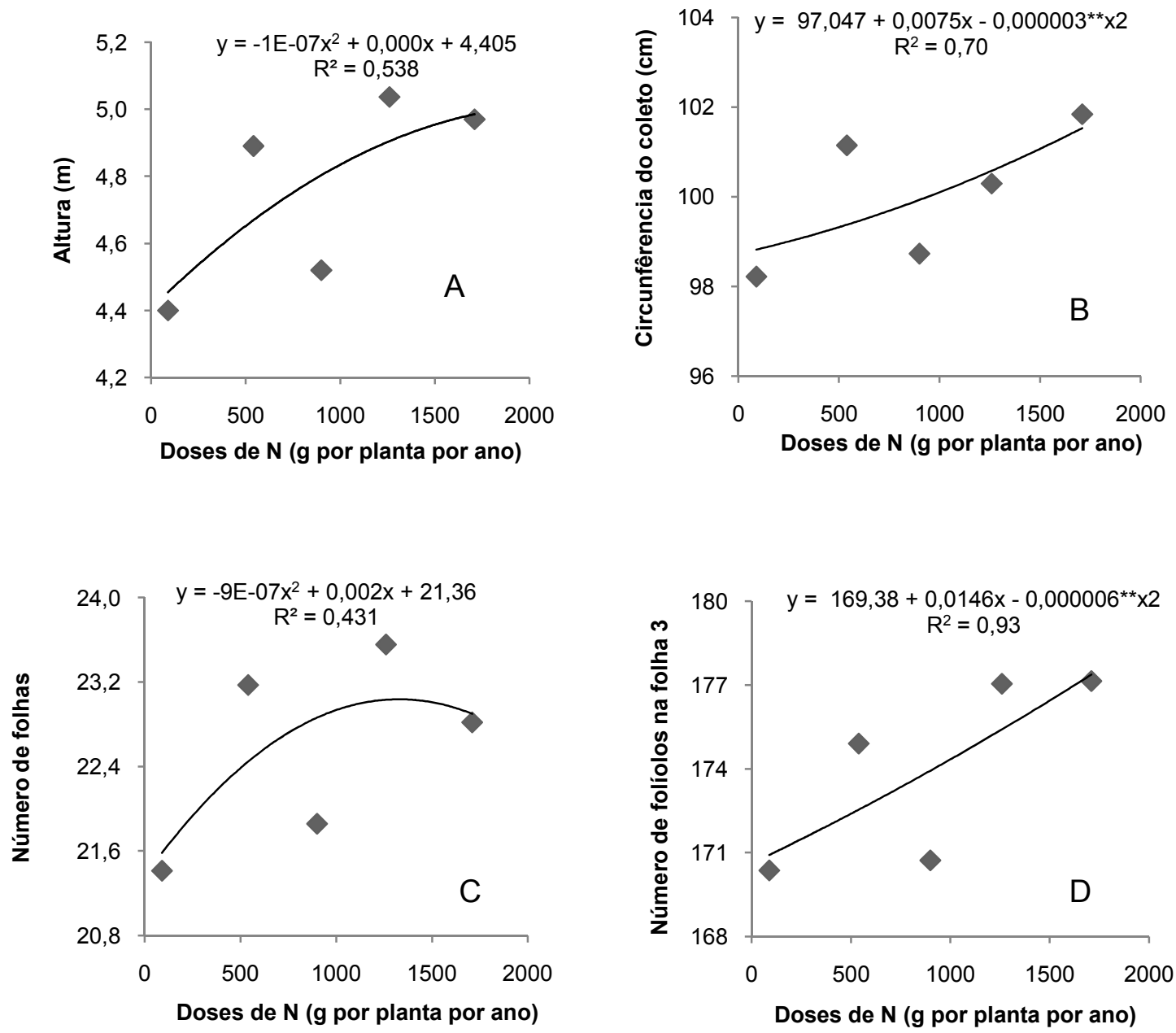

FIGURA 1 - Valores médios de altura (A), circunferência do coleto $(B)$, número de folha $(C)$ e número de folíolos na folha 3 (D) no terceiro ano do experimento de cultivo em função das doses de nitrogênio aplicados anualmente.

O aumento linear observado nas variáveis ALT, CC, NF e NFOL, evidencia que embora o uso da adubação nitrogenada tenha proporcionado efeito positivo no desenvolvimento das plantas, com as doses empregadas no espaço experimental não foi possível a obtenção de máxima eficiência física. Observou-se um efeito significativo nas variáveis NFF e NFP para as doses de $\mathrm{N}$ e $\mathrm{K}_{2} \mathrm{O}$ respectivamente, sendo o modelo quadrático o que melhor se ajustou (Figura 2 A e B). Verificou-se também que o aumento das doses de $\mathrm{N}$ diminuiu a quantidade de NFF. De acordo com a FAO (1984) o
$\mathrm{K}_{2} \mathrm{O}$ seria o principal responsável pelo NFF durante o período de produção e que, com o aumento das doses de $\mathrm{N}$ o efeito do $\mathrm{K}_{2} \mathrm{O}$ sobre a NFF cai em virtude do antagonismo destes nutrientes (Malavolta et al., 1997). Estes resultados também foram observados por Sobral (2003) que verificou que a cultura do coqueiro extrai uma enorme quantidade de potássio do solo na época da sua reprodução. De acordo com Marinho et al. (2006), uma maior produção de flores irá reproduzir uma maior quantidade de frutos por cachos dentro de condições adequadas para cultura. Em média o 
MATIAS, S.S.R. et al. Crescimento e produção de coqueiro...

NFP foi de 11,2 sendo considerados um resultado satisfatório para condições do experimento por
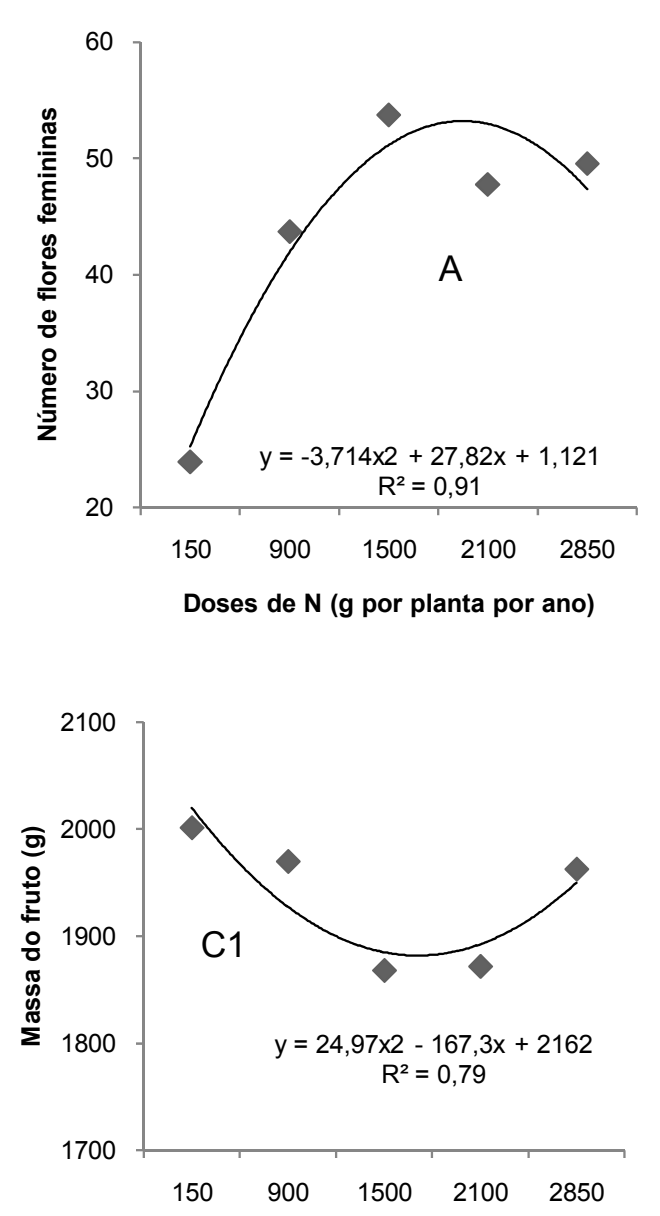

Doses de N (g por planta por ano)

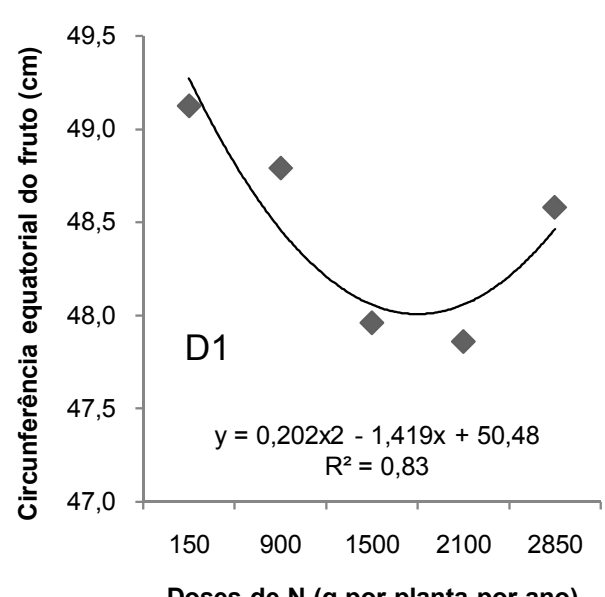

Doses de $\mathbf{N}$ (g por planta por ano)
Ferreira Neto et al. (2007), que obteve 11 NFP por média.
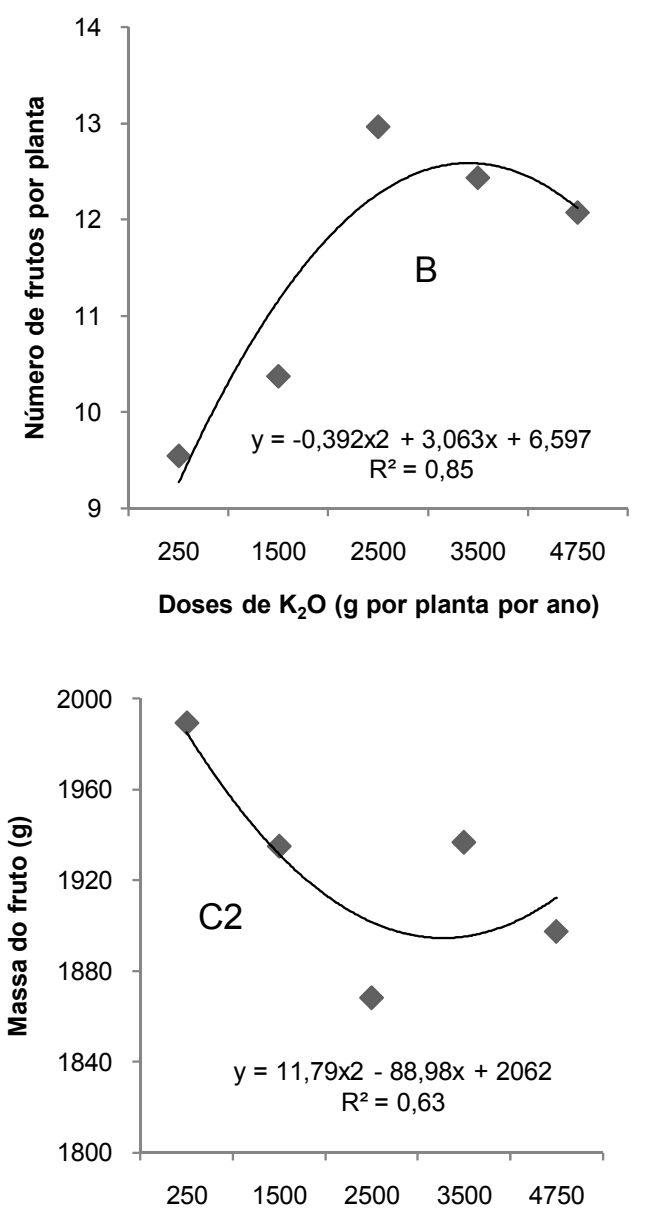

Doses de $\mathrm{K}_{2} \mathrm{O}$ (g por planta por ano)

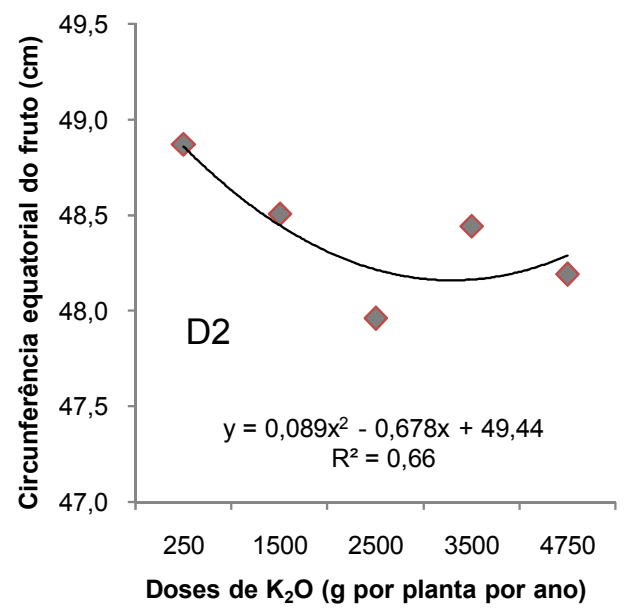

Figura 2 - Valores médios de número de flores femininas $(A)$; número de frutos $(B)$; massa do fruto (C1 e C2); circunferência equatorial do fruto (D1 e D2), no quarto ano do experimento de cultivo em função das doses de nitrogênio e potássio. 
MATIAS, S.S.R. et al. Crescimento e produção de coqueiro...

$\mathrm{O}$ incremento de $\mathrm{N}$ e $\mathrm{K}_{2} \mathrm{O}$ através da fertirrigação exerceu um efeito significativo $(P<0,05)$ na redução da MF, CEF, CPF e VA do coco (Figura 2 e 3: C1 e C2; D1 e D2; E1 e E2; F1 e F2).

Em geral, as menores doses obtiveram os maiores resultados nas variáveis de produção (Figura 2 e 3), o decréscimo dos valores obtidos por cada variável estudada na produção é provavelmente em função das altas doses de N. Os resultados estão de acordo com Miranda et al. (1999); Texeira et al. (2005) e Silva et al. (2006), que demonstram que o aumento das doses de $\mathrm{N}$ provoca diminuição no volume de água e tamanho do coco.

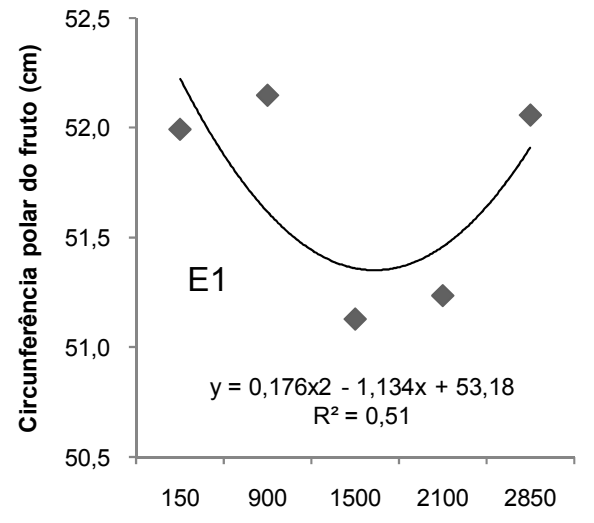

Doses de N (g por planta por ano)

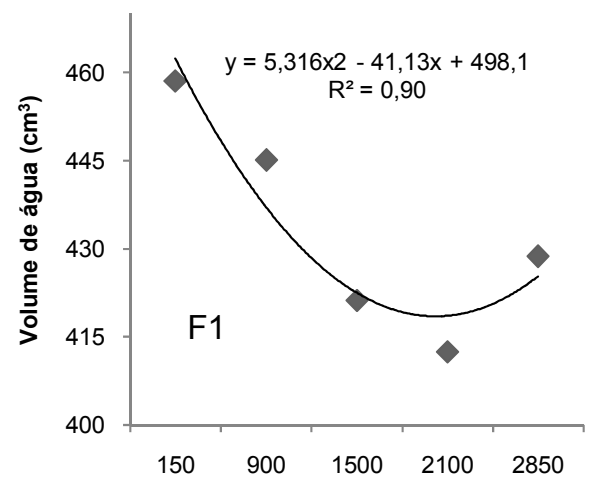

Doses de N (g por planta por ano)

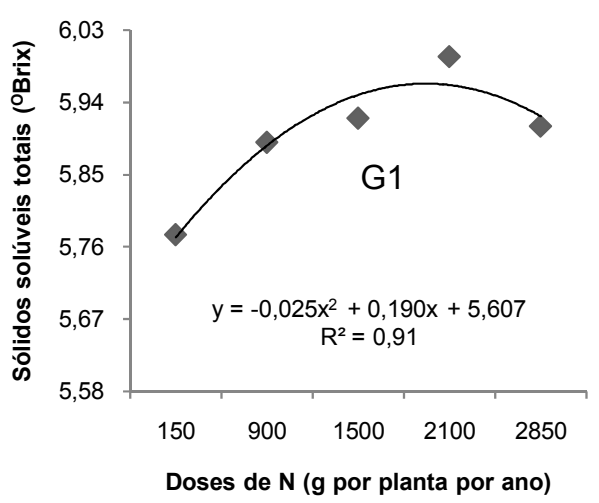

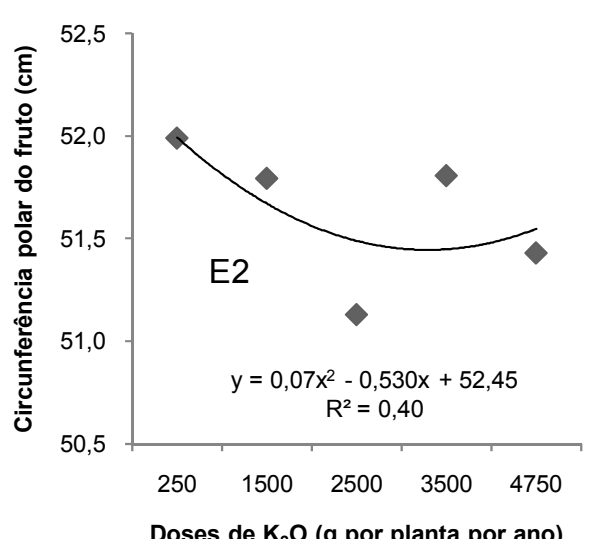

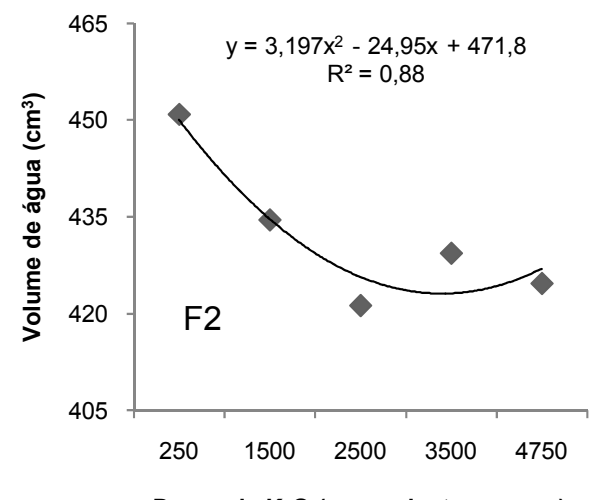

Doses de $\mathrm{K}_{2} \mathrm{O}$ (g por planta por ano)

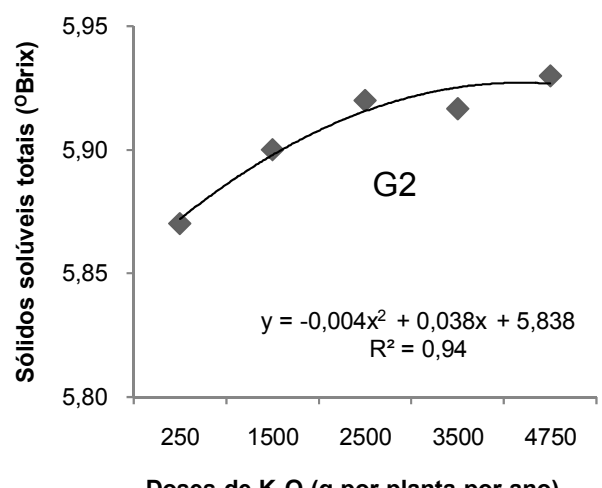

Doses de $\mathrm{K}_{2} \mathrm{O}$ (g por planta por ano)

Figura 3 - Valores médios de circunferência polar do fruto (E1 e E2); volume de água (F1 e F2); sólidos solúveis totais (G1 e G2) no quarto ano do experimento de cultivo em função das doses de nitrogênio e potássio. 
MATIAS, S.S.R. et al. Crescimento e produção de coqueiro...

Observa-se também que o volume médio da água de coco foi de $434 \mathrm{~cm}^{3}$ fruto $^{-1}$ e o máximo próximo a $460 \mathrm{~cm}^{3}$ fruto ${ }^{-1}$, com a menor dose de $\mathrm{N}$ (Figura 3). Estes valores são superiores aos obtidos por Camboim Neto (2002) e EMPARN (2001), respectivamente, 384 e $258 \mathrm{~cm}^{3}$ fruto ${ }^{-1}$.

No caso dos sólidos solúveis totais ( ${ }^{\circ} \mathrm{Brix}$ ), os nutrientes $\mathrm{N}$ e $\mathrm{K}_{2} \mathrm{O}$ influenciaram significativamente (Tabela 2). Verifica-se, na figura $3 \mathrm{G} 1$ e $\mathrm{G} 2$, que o aumento das doses $\mathrm{K}_{2} \mathrm{O}$ via fertirrigação, resultou no aumento do ${ }^{\circ} \mathrm{Brix}$, sendo o maior valor obtido com a maior dose $4750 \mathrm{~g}$ por planta por ano $\left(6,05^{\circ}\right.$ Brix $)$, sendo este mesmo valor encontrado por Miranda et al. (1999) em coqueiro anão verde do Jiqui. Silva et al. (2006) encontraram valores bem próximos aos obtidos neste estudo para $0{ }^{\circ}$ Brix $(5,9)$. De acordo com estes autores valores próximo de $6,0{ }^{\circ}$ Brix proporciona um sabor mais agradável na água de coco, promovendo assim uma maior aceitação por parte dos consumidores. Por outro lado, o incremento do $\mathrm{N}$ por fertirrigação diminuiu o valor de ${ }^{\circ}$ Brix na água de coco. Todavia, os valores de Brix encontrados no presente estudo, estão dentro de faixa normal e pouco superior aos valores observados por Lima et al. (2004), que encontraram o valor médio em torno de $5,5 \mathrm{em}$ condições edafoclimáticas do Rio de Janeiro.

\section{CONCLUSÕES}

1) As doses de $\mathrm{N}$ e $\mathrm{K}$ aplicadas no solo não afetam o número de cachos.

2) $\mathrm{O}$ aumento do $\mathrm{N}$ proporciona um crescimento linear nas variáveis altura, circunferência do coleto, número de folhas e número de folíolos na folha 3 .

3) As maiores doses de N promovem a diminuição das variáveis de produção com exceção do sólidos solúveis totais.

4) As maiores doses de $\mathrm{K}_{2} \mathrm{O}$ resultam em um aumento do número de frutos por planta e sólidos solúveis totais.

\section{REFERÊNCIAS}

1. ALVES, A. S. et al. Características morfológico-vegetativas de cultivares de coqueiro. Revista Brasileira de Fruticultura, v. 29, n. 3, p.518-523, 2007.

2. CAMBOIM NETO, L. de F. Influência de diferentes lâminas de irrigação e de porcentagens de área molhada no desenvolvimento, na produção e nos parâmetros físicoquímicos do fruto. 2002. 89 f. Tese (Doutorado em Engenharia Agrícola) - Universidade Federal de Viçosa, Viçosa, 2002.

3. CARRIJO, O. A. et. al. Tendências e desafios da fertirrigação no Brasil. In: FOLEGATTI, M. V. (Coord.) Fertirrigação citrus, flores, hortaliças. Guaíba: Agropecuária, 1999. p.155-169.

4. CHILD, R. Coconut. London: Longman, 1974. 335 p.

5. EMPARN. Empresa de Pesquisa do Rio Grande do Norte. Caracterização física do fruto e composição química da água de coco de cultivares Anão verde do Jiqui, Anão amarelo e Híbrido PB 121 aos 5, 6, 7, 8 e 9 meses de idade. In "Mini-curso" O cultivo do coqueiro. Fortaleza: Frutal, 2001. 102 p.

6. FOOD AND AGRICULTURE ORGANIZATION OF THE UNITED NATIONS (FAO). FAOSTAT. Disponível em:<http:/l faostat.fao.org/default.aspx>. Acesso em: 18 jan. 2005.

7. FERREIRA NETO, M. et al. Emissão foliar, relações iônicas e produção do coqueiro irrigado com água salina Ciência Rural, v. 37, n. 6, p.1675-1681, 2007.

8. FREMOND. Y.; ZILLER, R.; LAMOTHE, M. N. El Cocotero. Barcelona: Blume. Coleccion Agricultura Tropical, 1975 $236 \mathrm{p}$.

9. INSTITUTO BRASILEIRO DE GEOGRAFIA E ESTATÍSTICA (IBGE). Produção nos Estados. 2007. Disponível em: $<$ http://www.ibge.gov.br/estadosat/perfil.php?sigla=ce>. Acesso em: 28 jul. 2008.

10. LEITE, R. A. Uso de matrizes experimentais e de modelos estatísticos no estudo de equilíbrio fósforo-enxofre na cultura da soja em amostras de dois latossolos de Minas Gerais. 1984. 87 f. Dissertação (Mestrado em solos) - Universidade Federal de Viçosa, Viçosa, 1984.

11. LIMA, E. et al. Caracterização fisico-quimico da áqua de fruto do coqueiro anão verde, produzido no litoral sul de Rio de Janeiro. In: FERTIBIO, 5., 2004, Lages. Anais... Lages: UDESC/ SBCS, 2004. 1 CD ROM

12. MALAVOLTA, E.; VITTI, G. C.; OLIVEIRA, S. A. Avaliação do estado nutricional das plantas: princípios e aplicações. 2. ed. Piracicaba: POTAFOS, 1997. 319 p.

13. MARINHO, F. J. L. et al. Cultivo de coco anão verde irrigado com águas salinas. Pesquisa Agropecuária Brasileira v. 41 , n. 8, p.1277-1284, 2006.

14. MIRANDA, F. R.; OLIVEIRA, V. H.; MONTENEGRO, A. A. T. Desenvolvimento e precocidade de produção do coqueiro anão (Cocos nucifera L.) sob diferentes regimes de irrigação. Agrotropica, v. 11, n. 2, p. 71-76, 1999.

15. OCHS, R. Les contraintes écologiques du dévelopment des oléagineus pérennes (palmier et cocotier) em Afrique Occidentale et Centrale. Oléagineux, v. 32, n. 11, p. 461-477, 1977.

16. RAMOS, V. H. V. et al. Comportamento de cultivares de coqueiro anão e híbrido no Distrito Federal. Revista Brasileira de Fruticultura, v. 26, n. 2, p. 363-365, 2004.

17. SANTOS, H. G. et al. (Ed.). Sistema brasileiro de classificação de solos. 2. ed. Rio de Janeiro: Embrapa Solos, 2006. 306 p.

18. SAS Institute. Statistical analysis system for windows: computer program manual. Cary, 1995. $705 \mathrm{p}$.

19. SILVA, R. A. da et al. Qualidade de frutos do coqueiro-anão verde fertirrigado com nitrogênio e potássio. Revista Brasileira de Fruticultura, v. 28, n. 2, p. 310-313, 2006

20. SOBRAL, L. F. Nutrição e adubação. In: FONTES, H. R.; RIBEIRO, F. E.; FERNANDES, M. F. (Org.) Coco produção: aspectos técnicos. Brasília: Embrapa - SPI, 2003. p. 44-52. 
MATIAS, S.S.R. et al. Crescimento e produção de coqueiro...

21. TEIXEIRA, L. A. J.; SILVA, J. A. A. da. Nutrição mineral de populações e híbridos de coqueiro (Cocos nucifera L.) cultivados em Bebedouro (SP). Revista Brasileira de Fruticultura, v. 25, n. 2, p. 371-374. 2003

22. TEIXEIRA, L. A. J. et al. Adubação com NPK em coqueiro-anão verde (Cocos nucifera L.): rendimento e qualidade de frutos. Revista Brasileira de Fruticultura, v. 27, n. 1, p.120-123, 2005.

23. VILLAS BÔAS, R. L. et al. Perfil da pesquisa e emprego da fertirrigação no Brasil. In: FOLEGATTI, M. V. et al. (Coord.) Fertirrigação: flores, frutas e hortaliças. Guaíba: Agropecuária, 2001. p. 71-104.

Recebido em: 14/05/2009

Aceito em: 09/11/2009 